\title{
A formação continuada de professores de um município paulista segundo orientadores pedagógicos
}

\author{
The continuing teachers education of a paulista city according to pedagogical \\ counselors
}

\section{La formación continua del profesores de un municipio paulista segun consejeros pedagógicos}

\author{
Marco Aurélio Alves ${ }^{2}$ \\ Elvira Cristina Martins Tassoni ${ }^{3}$
}

\begin{abstract}
Resumo: Este artigo discute os princípios da formação continuada de professores dos anos finais do Ensino Fundamental, em uma rede municipal de ensino do interior paulista, entre 2010 e 2014. Identificaram-se as perspectivas acerca da formação continuada de professores, em documentos da Secretaria Municipal de Educação, e a prática educacional, segundo a visão de orientadores pedagógicos. Trata-se de um estudo de caso de abordagem qualitativa. $\mathrm{O}$ método incluiu a análise de documentos e entrevistas semiestruturadas com cinco orientadores pedagógicos e dois coordenadores responsáveis pela formação continuada no município. Os resultados indicaram que a rede de ensino tem optado pela constituição de modelos formativos antagônicos, de teores pragmáticos e neoliberais. Há diálogos desajustados entre as escolas e a Secretaria Municipal de Educação, fruto das condições de trabalho do professor, atravancando a consolidação da política de formação continuada de professores no município.
\end{abstract}

Palavras-chave: Formação de professores em serviço. Formação continuada de professores. Orientador pedagógico.

Abstract: This paper discusses the principles of continuing teachers education of the final years of the Elementary School from a municipal education network in the countryside of São Paulo from 2010 to 2014. It was identified perspectives on how the continuing teacher education should be according to documents from the Municipal Department of Education and the educational practices of pedagogical counselors. This is a study based on a qualitative research approach. The method included documents and semi-structured interviews analysis with five pedagogical coordinators and two educational counselors responsible for the continuing education programs in the city. The results show that the educational network has chosen an antagonistic program model: pragmatic and neoliberal. There are broken dialogues between schools and the Municipal Education Department, due to the teachers' environment conditions, blocking a consolidation of a continuing teacher education policy in the city.

Keywords: On-duty continuing teacher education programs. Continuing teachers education. Pedagogical coordinator.

Resumen: En este artículo se discute los principios de la formación continua de profesores en los últimos años de la Educación Primaria, en una red municipal de enseñanza del interior de São Paulo, entre los años 2010 y 2014. El estudio identificó las perspectivas involucradas en la formación continua de profesores, en documentos de la Secretaría Municipal de Educación, y de la práctica educacional, de acuerdo con el punto de vista de consejeros pedagógicos. Es un estudio de caso con enfoque cualitativo. En la metodología hay análisis de documentos y encuestas semiestructuradas, aplicadas a cinco consejeros pedagógicos y dos coordinadores encargados de la formación continua en el municipio. Los resultados indican que la red de enseñanza ha optado por la constitución de modelos formativos antagonistas, de contenidos pragmáticos y neoliberales. Resultado de las condiciones de trabajo del profesor, hay diálogos desarticulados entre las escuelas y la

\footnotetext{
${ }^{1}$ Submetido em: 08 jul. 2018 - Aceito em: 01 jul. 2019 - Publicado em: 24 dez. 2019

${ }^{2}$ Pontifícia Universidade Católica de Campinas (PUC-Campinas) - E-mail: marko.alves77@gmail.com

${ }^{3}$ Pontifícia Universidade Católica de Campinas (PUC-Campinas) - E-mail: cristinatassoni@gmail.com
} 
Secretaría Municipal de Educación que impiden la consolidación de la política de formación continua de profesores en el municipio.

Palabras clave: Formación del Profesorado. Formación continua de profesores. Consejero pedagógico.

\section{Introdução}

Este artigo é resultado de uma pesquisa ${ }^{\mathrm{i}}$ que busca discutir as seguintes problemáticas: como se constituiu a política de formação continuada de professores para os anos finais do Ensino Fundamental, entre 2010 e 2014 na rede municipal de uma cidade no interior paulista? Que aproximações e/ou distanciamentos são possíveis de se identificar entre o discurso oficial e a prática da Unidade Educacional (UE), segundo a visão de orientadores pedagógicos $(\mathrm{OP})$ ?

Para isso, realizamos um estudo de caso de abordagem qualitativa partindo de uma revisão bibliográfica sobre a formação continuada de professores (FCP) em direção à análise de documentos oficiais - utilizando os subsídios metodológicos de Bogdan e Biklen (1994) e André (1984) - além de entrevistas semiestruturadas com cinco orientadores pedagógicos vinculados a uma UE de cada região da cidade investigada e dois coordenadores responsáveis pela política de FCP do município.

As análises das entrevistas basearam-se nos pressupostos teórico-metodológicos de Aguiar e Ozella (2013), que propõem estratégias para apreender os significados e os sentidos atribuídos pelos sujeitos participantes à temática em questão.

A partir das entrevistas transcritas, realizamos leituras aprofundadas e sistemáticas a fim de selecionar trechos de falas dos participantes, nomeados por Aguiar e Ozella (2013) de pré-indicadores. A aglutinação desses pré-indicadores sugeriu eixos de análise mais amplos, denominados de indicadores, que apontaram para a elaboração de núcleos de significação. Segundo esses autores, a produção dos núcleos é um processo construtivo-interpretativo que deve representar aspectos centrais dos sujeitos e ser entendido como uma etapa na qual, "por meio da articulação dialética das partes, avança em direção ao concreto pensado, às zonas de sentido" (AGUIAR; OZELLA, 2013, p. 310).

Foram elaborados três núcleos de significação: (i) a compreensão sobre a formação continuada de professores e o papel de cada um dos envolvidos; (ii) o diálogo entre a escola e a Secretaria Municipal de Educação: organização dos cursos, oferta e jornada de trabalho; e, (iii) as influências da formação continuada de professores na escola e na prática docente: necessidades e mudanças. Mais adiante, apresentaremos cada um desses núcleos, trazendo o discurso oficial por meio das entrevistas com dois representantes máximos da Secretaria Municipal de Educação (SME) referentes à FCP - identificados como coordenadores 1 e 2 e pela fala da UE do ponto de vista dos OP - identificados como OP 1, OP 2, OP 3, OP 4 e OP 5.

Assim, organizamos o texto da seguinte maneira: breves observações acerca da política de FCP no Brasil; nosso olhar sobre as Diretrizes de Formação Continuada do município investigado; discussão a respeito dos núcleos de significação construídos, bem 
como algumas reflexões acerca dos princípios norteadores da formação continuada de professores e das supostas (in)coerências entre o discurso da SME e a prática da UE do município investigado.

\section{Algumas observações acerca da política de formação continuada de professores no Brasil}

Alguns estudos têm demonstrado que a FCP é considerada a chave para a melhoria da educação no país. Segundo Gatti (2008), no final do século XX, em países desenvolvidos, aumentou o discurso da atualização profissional constante, vista como pré-requisito importante para o mundo do trabalho, incluindo os sistemas educacionais.

Galindo e Inforsato (2008) alertam que, no mesmo período, o governo brasileiro passou a investir fortemente na FCP.

Davis et al. (2011) encontraram dois modelos relevantes que marcam as propostas de FCP: a) "modelo déficit", a partir do qual a FCP é pensada com base em possíveis fragilidades da formação inicial do professor, visando supri-las em uma perspectiva individualizada; b) modelo constituído com base no dinamismo da área educacional, reconhecendo a sua complexidade, bem como a intensa produção de conhecimento, geradora de novos modos de compreender o desenvolvimento humano $\mathrm{e}$ os processos de aprendizagem. Segundo este último, a FCP deve ser inerente à profissão docente por tratar-se de um campo que demanda atualizações constantes.

Contudo, Gatti (2008) aponta que a ampliação da FCP no país, em vez de atuar no aprofundamento de conhecimentos, tem sido encarada mais como uma forma de amenizar as fragilidades da formação inicial. Ainda de acordo com a autora, a equação (não necessariamente verdadeira) diz respeito a uma ideia de que a melhoria dos processos educativos acarretaria uma melhoria da economia por meio da "qualificação das pessoas para a sociedade do conhecimento e do consumo" (GATTI, 2008, p. 63). Logo, Gatti (2008) denuncia que uma FCP baseada em uma perspectiva material e econômica deixa de lado as preocupações com a formação humana.

Saviani (2008) faz um balanço entre 1991 e 2001, contribuindo para reflexões acerca das influências das reformas educacionais nos programas de FCP, que, desde os anos de 1990, vêm assumindo um caráter mais pragmático em um movimento iniciado com: a valorização da requalificação dos trabalhadores (neoprodutivismo); a ideia que o professor deve ser o mediador do processo de aprendizagem (neoescolanovismo); a preocupação em subsidiar uma sociedade marcada pela diversidade (neoconstrutivismo); por fim, a centralização na "formação" que concebe o professor como prestador de serviço, o aluno como cliente e a educação como um produto (neotecnicismo). A partir dos estudos de Saviani (2008), foi possível notar o quanto a educação está, cada vez mais, nas mãos da iniciativa privada, sem os devidos cuidados com a qualidade desejável.

De acordo com Maués (2003, p. 101), a ênfase nos aspectos práticos da formação de professores ocorre em razão de um contexto internacional que acredita que o futuro docente 
necessite ter um contato "[...] real com o meio em que deverá atuar, devendo, desde o início da formação, assumir tarefas específicas e ter um acompanhamento direto para a realização delas". Para a autora, as reformas educacionais internacionais justificaram-se diante do argumento de que "os cursos de formação têm sido muito teóricos, desvinculados do meio escolar $[\ldots] "$.

Tanto Saviani (2008) como Gatti (2008) têm apontado o Brasil como signatário dessas reformas educacionais internacionais, incentivando a FCP em instituições privadas de qualidade duvidosa, bem como a valorização da prática em detrimento da teoria ou da práxis.

No entender de alguns pesquisadores, como, por exemplo, Scalcon (2008), a práxis é fundamental no âmbito da formação do professor, pois, possibilita a interpretação do mundo visando transformá-lo. Para essa autora, a práxis leva em consideração "a essência da realidade captada pelo concreto pensado e em consideração ao movimento dialético de elaboração de conhecimentos que vai da prática à teoria" com vistas a encontrar relações entre o micro e o macro (SCALCON, 2008, p. 504).

Nesse sentido, a epistemologia da práxis, na dimensão da formação do professor, assume também o papel de mediadora, pois possibilita a identificação dos “[...] limites de uma ação pedagógica fundada em processos de formação alienados e desumanizadores porque assentados na hegemonia dos valores da classe dominante" (SCALCON, 2008, p. $505)$.

Assim, parece-nos razoável compreender que a epistemologia da práxis é mais ampla, uma vez que considera as relações sócio-históricas, permitindo ao professor uma visão mais global na interpretação do mundo e, consequentemente, na intenção de transformá-lo.

\section{As diretrizes de formação continuada no município em questão}

Em 2010, a SME do município investigado, elaborou, com base em uma Comissão de Conselho Consultivo Pedagógico, formada por seis especialistas (a saber: um coordenador da Setorial de Formação, dois orientadores pedagógicos e três coordenadores pedagógicos), um documento apresentando as Diretrizes de Formação Continuada aos Profissionais da Educação. Durante todo esse processo, foi possível obter a participação dos professores e observar que nem todas as proposições da Comissão foram bem aceitas por eles.

Dentre os tópicos polêmicos está a questão da dedicação exclusiva: o coletivo dos professores reivindicou a não obrigatoriedade de concentração do docente em apenas uma UE, além da diferenciação dos tempos coletivos e do tempo para a preparação de aula, não havendo a diminuição dos primeiros em favor do segundo nem da FCP de caráter facultativo.

Destacamos no documento três aspectos relevantes que tratam da FCP. O primeiro refere-se à formação como um direito e um dever. No entanto, o município descumpre o Artigo 67, inciso II da Lei de Diretrizes e Bases da Educação Nacional (LDBEN) 9394/96 (BRASIL, 1996), segundo o qual o profissional da educação possui direito à licença remunerada para concluir cursos de pós-graduação. Nas disposições legais do município 
investigado, não há menção referente à possibilidade de qualquer tipo de afastamento (remunerado ou não) para a realização de formação nesse nível. Encontramos apenas referências à afastamentos remunerados para a participação dos professores em eventos de curta duração, como Seminários, Encontros, Colóquios e Congressos. O caminho encontrado para garantir o legislado na LDBEN/96 tem sido o judicial.

O segundo aspecto que rege a política de FCP no município é a consideração desse tipo de formação como inerente ao trabalho do profissional da educação, alinhando-se com os estudos de Davis et al. (2011). No entanto, o município não oferece condições concretas nessa direção, pois descumpre a Lei $\mathrm{n}^{\circ} 11.738 / 2008$, que trata do piso salarial (BRASIL, 2008) e estabelece a interação do professor em, no máximo, 2/3 (dois terços) de sua carga horária com os alunos, destinando $1 / 3$ da jornada de trabalho à realização de atividades fora da sala de aula, sem a presença dos alunos. Assim, ao não se garantir esse direito, a formação continuada permanece no âmbito do esforço e da iniciativa individual do docente.

O terceiro aspecto ligado às Diretrizes de Formação refere-se à explícita intenção de combater, no plano teórico, as ideologias liberais, defendendo um trabalho coletivo para o desenvolvimento profissional. Embora o documento tenha o propósito de promover uma ampla discussão sobre a FCP, há muitos desafios a serem enfrentados diante das contradições existentes no âmbito da Prefeitura Municipal, por exemplo, na constituição de parcerias público-privadas. As empresas não explicitam como seria a atuação na $\mathrm{FCP}$, mas evidenciam uma forte atuação nos processos de gestão. Mas não vamos detalhar essas questões, pois extrapolam os limites desse texto.

\section{Os cursos e grupos formativos propostos pelo município}

Analisando a oferta de cursos e grupos formativos da SME (grupos de estudo, de trabalho e de formação), entre os anos de 2010 e 2014, observamos que eles são oferecidos aos professores por meio de listas publicadas em Diário Oficial (DO). No período averiguado, a SME ofertou 361 formações aos professores de anos finais. A oferta de tais formações segue a orientação das Diretrizes de Formação, que destacam algumas áreas prioritárias para a formação, como fundamentos da educação, práticas pedagógicas, linguagens, avaliação, metodologia e inovação.

Tendo em vista as contribuições metodológicas de Bogdan e Biklen (1994) e André (1984), tais formações foram listadas em planilha cuja leitura recorrente da ementa sugeriu uma forma de categorização evidenciando as tendências de oferecimento, que foram organizadas em 11 (onze) eixos temáticos, a saber: 1) Educação Especial; 2) Mídias, Comunicação e Tecnologias; 3) Sexualidade, Gênero e Relações Étnico-Raciais; 4) Arte e Cultura; 5) Idiomas; 6) Referencial teórico-prático dos Componentes Curriculares e Educação de Jovens e Adultos (EJA); 7) Meio Ambiente; 8) Saúde e Cidadania; 9) Leitura, Escrita e Trabalho Pedagógico; 10) Educação Integral; e, 11) Relacionamentos, Enfrentamento de Conflitos e Valores. 
Foi possível constatar que a maior parte dos temas citados mantiveram-se recorrentes ao longo dos cinco anos pesquisados. Contudo, a partir de 2013, notamos o aparecimento de cursos e grupos formativos acerca da Educação Integral e de Relacionamentos, Enfrentamento de Conflitos e Valores. Observamos uma grande variedade de temas, além do surgimento de outros, o que indica, novas preocupações do governo municipal, por exemplo, cumprir o decreto $\mathrm{n}^{\mathbf{0}} 7.083$, de 27 de janeiro de 2010, segundo o qual os municípios devem fornecer gradualmente a educação integral (BRASIL, 2010).

Por fim, apresentamos algumas expectativas: As temáticas ofertadas pela SME atendem às demandas dos professores e das UE? Apesar da grande oferta de formações, os professores participam das FCP? As decisões pelas temáticas são feitas a partir de um diálogo entre o Centro de Formação Continuada e as UE? As formações impactam no trabalho docente? Entendemos que a articulação das análises dos documentos e das entrevistas tenha sido fundamental para encontrarmos algumas respostas ou novas perguntas. Tais questionamentos nortearam o processo analítico e deram base para a construção dos núcleos de significação apresentados a seguir.

\section{Os núcleos de significação}

Conforme exposto na introdução deste artigo, com base no material empírico, discorreremos sobre três núcleos de significação elaborados.

\section{A compreensão sobre a formação continuada de professores e o papel de cada um dos envolvidos}

Aqui discutiremos as concepções de FCP expressas pelos participantes da pesquisa e suas influências no desenvolvimento da docência e das funções mais específicas, como orientação, coordenação e direção.

De maneira geral, tanto os OP como os coordenadores entendem que a FCP deva ser continuada. Entretanto, enquanto as falas dos coordenadores tratam exclusivamente da concepção de FCP, as falas dos OP entrevistados compreendem a FCP de maneira relacionada com as necessidades da UE:

Eu entendo por formação continuada toda formação que se faz ao sair da faculdade. Da formação inicial e entrando no mercado de trabalho você tem que continuar estudando, então, todo esse estudo contínuo que vem depois da formação inicial é formação continuada e eu entendo a formação continuada como sem fim, não tem um limite [...] (Coordenador 1).

[...] ela é uma ação perene. A partir do momento que você conclui a graduação enquanto os professores profissionais da educação que nós somos [...] (Coordenador 2). 
Quatro dos cinco OP entrevistados referem-se à FCP como um estudo contínuo que deve envolver, sobretudo, as questões de ordem prática, tendo a escola e a sala de aula como finalidade:

O que eu entendo por formação continuada é a busca que a gente tem quase que diária. Até pelas necessidades dentro da escola, e as práticas vão levando, apontando algumas necessidades, e na educação isso é muito comum, isso é muito fácil de visualizar, a gente está sempre conversando, a gente sempre está trocando e um vai ajudando o outro, até buscar o que a gente quer aperfeiçoar, onde a gente quer continuar estudando. Então, eu acho que é uma necessidade do dia a dia (OP 2).

Formação continuada de professores, pra mim, é aquele estudo que você faz dentro do próprio trabalho, envolvendo suas próprias atividades, ele não tem valor nenhum se ele for bastante teórico, está bem totalmente ligado à ação do professor na sala de aula (OP 5).

Notamos que essas demandas por uma FCP mais pragmática estão muito mais relacionadas à urgência na resolução de problemas do cotidiano escolar do que propriamente por uma opção teórico-metodológica, tal qual sugere Schön (2000) ao tratar de uma epistemologia da prática.

Este tipo de discurso não é privilégio de certos docentes, mas também dos que ocupam cargos de confiança com relevância política. Um dos coordenadores, ao ser perguntado acerca da importância da FCP para a SME, afirma:

Veja! Esse ano [2014] nós tivemos mais de 100 ações de formação continuada [cursos e grupos formativos] pelo Centro de Formação. É então por esse número que dá para ver a importância que tem essa política para nós da rede municipal (Coordenador 2).

Apesar do esforço dessa SME em ofertar um número expressivo de cursos, passando de 36 cursos em 2013 para 83 em 2014, com o intuito de atender as diferentes necessidades dos professores em um município de grande porte, entendemos que esse coordenador trabalha com a concepção de que a relevância da FCP está na quantidade de formações.

Já o OP 1, ao ser perguntado sobre seu ponto de vista, explica que "é uma política, ela tem uma vitrine muito boa", fazendo referência à grande quantidade de formações ofertadas pelo poder público, mas questionando se o objetivo principal é de fato a FCP ou se trata-se apenas de demonstração de que muito se faz pela educação. Tal questionamento é embasado na constatação de que o número de docentes que participam delas efetivamente é muito reduzido.

São poucos [que participam da formação], nós fizemos uma lista para colocar no PPP [Projeto Político Pedagógico], professor por professor. Perguntamos para eles "você está na formação? Que formação você está? E, se não conseguiram estar [em formação], por quê?". Assim, 70\% respondeu: "não estou [em formação] por conta do acúmulo". Entendeu? [...] A maior parte [dos professores] está trabalhando em outra escola e não tem o tempo mínimo para ele estar na escola e o que ele tem de TDPA [Trabalho Docente para a Preparação de Aulas] é o tempo mínimo pra correção de prova (OP 5). 
Os professores mais antigos eles têm esse tempo pedagógico, a CHP [Carga Horária Pedagógica] que permite ainda e ajuda um pouco, mas os [professores] novos não. Aos adjuntos também não, então não é suficiente porque se ele trabalha em duas unidades é uma série de coisas que tem aí (OP 3).

Por outro lado, temos exemplo de OP que considera o fator quantitativo por si só significativo: "nós temos muitos cursos oferecidos. Logo, aqui [no município em questão], nós temos uma rede que olha bastante para essa questão da formação" (OP 2).

Consideramos que, como política educacional, a questão da grande oferta de curso de formação continuada para os professores é necessária e importante, mas não acreditamos que seja suficiente como um fim em si mesmo. As políticas educacionais devem também investir em outros mecanismos que viabilizem maior participação e envolvimento dos professores.

De qualquer forma, independentemente das supostas divergências entre as concepções de FCP dos representantes da SME e dos OP, é interessante sinalizar que os OP entendem seu papel mais como mediadores na indicação das formações divulgadas no Diário Oficial Municipal (DOM) do que propriamente formadores.

Em entrevista com esses profissionais, ao serem indagados a respeito de seu papel com relação à FCP, dos cinco entrevistados, quatro enfatizaram seu papel de incentivar, indicar cursos de formação ou meramente informar sobre a publicação da lista de cursos no DOM.

Suspeitamos que essa dificuldade em compreender o papel formativo esteja vinculada a três fatores principais: a falta de clareza nas normas acerca de seu papel formador; a relativa demora na definição das Diretrizes de Formação dos Profissionais da Educação e a ausência de uma formação ao OP que subsidie a FCP. Ao salientar a não compreensão dos documentos normativos referentes às atribuições dos OP, ressaltamos que há uma Lei Municipal de 2007 que explicita o papel dos orientadores pedagógicos, mas inferimos que é necessário incluir em tais documentos normativos, bem como no regimento escolar, referências à Lei Municipal de 2007, como forma de resgatar e fazer circular com mais frequência as atribuições dos OP, incluindo o caráter formativo.

Na referida Lei, o Orientador Pedagógico possui um papel importante na condução da formação continuada de professores:

Corresponsabilizar-se pela organização e orientação da equipe educacional para que esta possa cumprir a tarefa de ensinar os conteúdos registrados no plano escolar/projeto pedagógico, avaliando e reorganizando periodicamente o trabalho pedagógico; corresponsabilizar-se pelo planejamento e avaliação das atividades pedagógicas realizadas pela equipe educacional, tendo em vista a autonomia e a formação integral discente; responsabilizar-se pelo planejamento, elaboração, sistematização, implementação e avaliação do projeto pedagógico; promover e coordenar reuniões pedagógicas periódicas com os profissionais da unidade educacional, inclusive as relativas à avaliação institucional, considerando a implementação das políticas educacionais da SME; planejar, coordenar, implementar e avaliar seminários, grupos de estudo, palestras, oficinas e outras atividades para o aperfeiçoamento da práxis pedagógica dos profissionais da unidade educacional; executar, acompanhar e avaliar as ações previstas no plano escolar/projeto pedagógico para melhoria dos indicadores educacionais; acompanhar o plano de ensino dos professores oferecendo subsídios para o aperfeiçoamento do processo de ensino/aprendizagem, com especial atenção aos 
resultados da avaliação discente; buscar continuadamente o assessoramento dos coordenadores pedagógicos da SME tendo sempre presente os objetivos registrados no plano escolar/projeto pedagógico e as diretrizes educacionais da SME (DIÁRIO OFICIAL MUNICIPAL) ${ }^{\mathrm{ii}}$.

As entrevistas com os OP indicaram que a falta de uma formação de qualidade voltada aos especialistas contribui para que eles não se reconheçam como formadores. Além disso, não há como negar a necessidade de condições objetivas mínimas que permitiriam ao OP trabalhar a "formação do professor", como mais tempos pedagógicos coletivos.

Contudo, é factível inferir, por meio das entrevistas, que tais indefinições se relacionem com a carência de uma Diretriz de Formação resultante de uma política de Estado.

A não conclusão do documento das diretrizes para a formação de professores, desde 2010, tem sido interpretada de maneira diferente pelos coordenadores entrevistados. Por um lado, tal inconclusão relaciona-se à grande rotatividade de pessoas que ocupam cargos de chefia, fundamentais na política de FCP. O Coordenador 1 relata:

Eu acho que por conta mesmo da mudança de governo, o primeiro em 2010, mudou o governo e não acabou. O próximo governo teve interesse [de continuar a produção do documento] [...], mas depois a secretária [de Educação] ficou doente [...] e aí a comissão sumiu e ninguém mais continuou.

Ao mesmo tempo, o Coordenador 2, embora defenda a importância da elaboração de diretrizes para a formação de professores, considera que o município já tem estruturado uma política consolidada e, por isso, independente do partido que está à frente do governo:

Se configura como uma política de Estado, não como uma política de governo, então os partidos políticos, as administrações que vão entrando para cuidar da administração pública do município incorporam isso por conta da importância que tem essa política para o município [...] e é constituído não é? Já está constituído (Coordenador 2).

Certamente, a inconstância das pessoas nos cargos estratégicos para FCP também contribui para a morosidade nesses processos, mas há indícios, no material empírico produzido, de que alguns aspectos relacionados à política de formação de professores estão consolidados. Observamos, porém, que a demora na conclusão do documento sobre as Diretrizes de Formação de Professores também se relaciona com questões ainda difíceis de serem resolvidas, a exemplo dos conflitos de interesses entre os profissionais da educação no interior da rede de ensino. Enquanto a Comissão do Conselho Consultivo Pedagógico da SME sugere que se faça necessário superar algumas condições objetivas, como manter o profissional da educação em regime de dedicação exclusiva a uma UE e ampliar o Trabalho Coletivo Docente (TDC) na escola, os profissionais da educação repudiaram tais propostas em relação à forma como foram colocadas.

Reparamos que os próprios professores não aceitaram manter-se em uma única UE e negaram a ampliação do TDC (momento de planejamento de atividades, mas também de formação continuada), o que aparentemente os beneficiaria. Isso ocorre porque existem docentes que trabalham há anos em outras redes, públicas e/ou privadas, e, dessa forma, 
teriam que deixar uma delas. Da mesma maneira, a expansão da carga horária do TDC (para além de suas 02h/aulas) poderia prejudicar professores que lecionam em outras UE na medida em que poderiam existir conflitos de horários ou exceder a carga horária semanal permitida. Há que se ressaltar que esses mesmos professores que atuam em mais de uma UE fizeram tal escolha, no passado, em razão da desvalorização salarial sofrida pela categoria há décadas. Portanto, se o professor tem acúmulo de cargos, terá menos ou nenhum tempo para investir em sua formação.

Notamos, assim, que as mudanças de governo, de pessoas e os conflitos de interesses alteram os direcionamentos da FCP, daí as indefinições de papéis dos envolvidos e a falta de clareza relatada pelos OP.

No entanto, com base nas entrevistas com os OP, entendemos que as definições dos cursos e grupos formativos não devem ser realizadas "de cima para baixo", isto é, sem a participação das UE. Os OP afirmaram a inexistência dessa conversa entre a SME e as escolas:

Então a gente percebe que às vezes tem cursos que chega com horário inadequado às vezes com ementa inadequada. $\mathrm{E}$ se fosse mais discutido [as definições dos cursos de formação] acho que seria mais proveito, falar o que vocês esperam, o que vocês procuram. [...] em momento algum é feito essa conversa nem com a gente em assessoramento (OP 4).

O OP 4 ainda acrescenta que "é mais uma pesquisinha que o pessoal da formação faz", referindo-se a uma consulta rápida e com um grupo pequeno vinculado ao Centro de Formação. Portanto, é preciso um maior diálogo entre a SME e a UE, conforme discutiremos no próximo núcleo de significação.

\section{Diálogo entre a escola e a SME: organização dos cursos, oferta e jornada de trabalho}

Como se dá a relação entre a SME e as UE quanto à FCP? Do ponto de vista dos OP, é preciso rever os critérios de definições das formações:

\footnotetext{
A gente questiona quem é que define essa formação. Tem alguns cursos que, não que não sejam interessantes, mas dentro do contexto da rede é importante que se faça curso de dança circular? Sabe, às vezes, a gente fala, de onde que veio essa necessidade? (OP 1).
}

Se, por um lado, o OP 1 pode demonstrar uma visão pragmática na medida em que imagina que as formações devam ter uma relação direta com a prática do professor, por outro, para tal OP, é difícil entender os critérios de escolha das temáticas tratadas nos cursos de formação. O documento não concluído das Diretrizes de Formação aponta que a FCP no município se pauta por

Estudos e implementação das várias linguagens que comportam a formação humana, com destaque para o campo das Letras, das Artes, da Comunicação e das Tecnologias considerando o letramento nas múltiplas linguagens aspecto central a 
ser fomentado nas variadas modalidades formativas (FUNDAMENTOS $\mathrm{E}$ DIRETRIZES $S^{\mathrm{iii}}$ ).

Inferimos que, embora haja a defesa de uma formação humana como base para os princípios norteadores do planejamento e a seleção dos cursos de formação, tal critério deva ser discutido e explicitado claramente. Nesse sentido, observamos que há riscos de se compreender a oferta da formação de maneira dissociada da prática, o que gera como consequência a valorização desta em detrimento da teoria (SAVIANI, 2008; GATTI, 2008). Da mesma forma, o risco de deixar a formação humana de lado traz fortes impedimentos para o movimento dialético de reflexão, que possibilita transformações (SCALCON, 2008). Enquanto não se avançar em definições urgentes e necessárias em relação: (i) à composição da jornada contemplando a formação; (ii) à regulamentação clara de licença remunerada para a formação; (iii) à oferta da formação juntamente com o processo de escolha de aulas; e, (iv) ao regime de dedicação exclusiva, os desafios para a construção de uma política para a formação de professores ainda serão grandes.

Segundo o Coordenador 1 , as demandas em relação às definições dos cursos oferecidos surgem de uma articulação entre os Coordenadores Pedagógicos (CP) e os OP, levando em consideração ainda as discussões em âmbito nacional, as demandas da SME e a implementação das Diretrizes Curriculares do município.

O Coordenador 1, ao ser perguntado se o Centro de Formação consulta os Projetos Políticos Pedagógicos (PPP) para verificar as demandas das UE, afirma que

Deveria consultar, não digo que está acontecendo isso. Como as pessoas conhecem os PPP, os CP e nessa relação com os OP, então a gente tem essa facilidade, mas eu não vou dizer para você que é uma diretriz consultar os PPP, não é isso, vai lá e consulta, é mais na articulação com os OP (Coordenador 1).

Devemos reconhecer que a FCP, em razão de sua especificidade em atender as tendências contemporâneas de atualização constante, deve mudar conforme as necessidades de um determinado tempo histórico (GATTI, 2008). No entanto, o que notamos é que tais mudanças e/ou permanências ocorrem de forma centralizada e sem a participação de professores e OP. Apesar de o Coordenador 1 afirmar que há uma articulação com os OP nas definições das FCP, os OP entrevistados afirmam que não são contemplados em tal processo: "A gente nunca é chamada para buscar, pensar junto a formação. Seria interessante como orientador pedagógico, pois a gente está dentro da escola e está vendo o que falta de fato" (OP 1).

Todavia, é inegável que esses diálogos entre a SME e as UE sofrem interferências da estrutura organizacional dessa atual rede de ensino, que impossibilita a participação mais consistente de professores e OP. Tal relação é reconhecida pela própria SME na fala do Coordenador 2, ao afirmar que há "a necessidade de colocar na jornada do professor o momento da formação continuada, pois [...] muitos deles têm que ter mais de uma jornada de trabalho em outras instituições [...]" (Coordenador 2).

Essa fala vai ao encontro da afirmação do OP 5, ao revelar que cerca de 70\% de seus professores trabalham em outra UE, dificultando a participação em formações. 
No entanto, para o Coordenador 1, a falta de participação dos docentes na formação relaciona-se a outros fatores. Isso indica que, para esse representante da SME, a responsabilidade da não participação dos docentes nas formações ainda recai sobre a UE e o próprio professor. Dessa forma, observamos que não há concordância entre os dois principais representantes da SME quanto aos fatores que impedem a participação da maioria dos professores nas formações oferecidas pela SME.

Isso fica mais evidente quando o Coordenador 2 admite que, com o cumprimento da Lei do Piso Salarial, há a necessidade de fazer valer o artigo $4^{\circ}$ da Lei 11.738/2008, que destaca que a jornada de trabalho do professor deve estar comprometida em, no máximo, 2/3 com atividades envolvendo alunos (BRASIL, 2008).

Até o final desta investigação, a SME cumpria o artigo $4^{\circ}$ da Lei do Piso somente para as cinco escolas de educação integral. Os professores das demais UE estão à margem dessa nova jornada, o que impede a maciça presença nos momentos de FCP, apesar da certificação e da remuneração dessas formações.

\section{Influências da formação continuada de professores na escola e na prática docente: necessidades e mudanças}

Como tratar dos efeitos da FCP na prática docente? Sem dúvida, faz-se necessário apontar as condições às quais os professores desse município estão submetidos. Nas entrevistas com os OP e com um dos coordenadores, percebemos que a falta de tempo do professor é um dos maiores problemas que afeta a sua realização ou qualidade. Não por acaso, o Coordenador 1 reconhece a pouca participação dos professores nas formações (ainda que remuneradas) ao afirmar que "nós estamos atendendo hoje [agosto de 2014] 50\% dos professores".

Além das dificuldades em relação ao tempo do professor, os OP não observaram mudanças significativas nas práticas pedagógicas e na UE. As falas dos OP indicam que existem professores que participam das formações meramente para adquirirem certificados e, consequentemente, obter benefícios financeiros previstos nos planos de cargos, que, por vezes, não observam mudanças na didática das aulas dos docentes, sem contar a dificuldade em socializar os novos conhecimentos aprendidos nas formações com os seus pares, em razão da falta do tempo pedagógico:

\footnotetext{
Então a gente nem sempre vê esse retorno [das formações que os professores realizam], [...] é muito difícil, o professor que vai fazer um curso de matemática ele vir e trabalhar em relação ao que ele está discutindo. Não consegue [ver um retorno da FCP] ainda mais que a escola se aparelhe para dar o suporte para os professores desenvolverem, lamentavelmente isso, é até fala de algumas pessoas, faz porque tem o certificado, sabe algum benefício vai trazer, agora o benefício da devolução da qualidade fica meio prejudicado, a gente não percebe muito isso não (OP 1).
}

A partir das entrevistas com os OP, observamos que a formação no município em questão pouco se articula com a jornada de trabalho dos professores, já que a oferta da formação acontece posteriormente à atribuição das aulas. Portanto, os professores fazem suas 
escolhas conforme a disponibilidade de seu horário. Vemos que, para de fato atender aos interesses e necessidades do professor e da escola, seria importante que o movimento fosse o inverso: primeiro a disponibilização dos cursos e depois a atribuição de aulas.

Eu acho que ela demora muito [a divulgação das ofertas de formações], primeiro assim, a relação do que é oferecido, ela não condiz com o início do ano, nós já estamos em abril e não temos a relação de cursos oferecidos pela rede, não saiu no diário oficial, então eu acho que para organização do professor ela fica ruim. E muitos cursos interessantes eles não são oferecidos, eu acho que tem que ser oferecidos nos três períodos porque hoje a gente sabe que o professor se divide em várias unidades. [...] Eu acho que ela tem que ser divulgada antes da atribuição do professor pra organizar melhor a vida em relação à qualidade [...] (OP 4).

Em uma perspectiva individualista de formação continuada, destacamos que tanto a diversidade de oferta de cursos, como a busca e o envolvimento pessoal do professor levam a um processo formativo pouco articulado com mudanças efetivas dentro das escolas. Enquanto as formações não agregarem o coletivo da escola, haverá riscos eminentes de frágeis contribuições para mudanças. Segundo Davis et al. (2011, p. 830) o modelo individualista visa

superar as mazelas deixadas pela formação inicial. Essa abordagem centra-se, sobretudo, nas características que faltam aos docentes e, por isso, é denominada de "abordagem do déficit". Esse modelo pressupõe que os professores pouco ou nada têm a dizer sobre como aprimorar sua formação, motivo pelo qual não podem ser consultados sobre essa questão. A FCP é, portanto, definida em outras instâncias e/ou por níveis hierárquicos superiores dos sistemas de ensino, desconsiderando-se as especificidades dos professores e de seus locais de trabalho. São propostas uniformes, no formato "tamanho único" e "unissex", cuja meta é atingir o conjunto dos professores, independentemente de sua idade, tempo de experiência, disciplina lecionada e interesses.

Uma FCP sustentada no individualismo evidencia-se na medida em que a SME define as ofertas de formações sem uma articulação com docentes e OP. Logo, os cursos formativos são disponibilizados a todos os docentes, mas não necessariamente atendem às suas reais demandas, bem como às demandas das UE. Do ponto de vista da SME e diante da grande oferta de cursos, cabe ao professor estudar para se aperfeiçoar ou sanar suas defasagens da formação inicial, independentemente da real possibilidade de o docente poder realizar tais cursos. Isso nos faz suspeitar de uma silenciosa visão neoliberal, em que, de acordo com Lima (2007), tanto o sucesso quanto o fracasso ficam sob a responsabilidade do indivíduo, isto é, do próprio professor e/ou da UE. Isso fica mais nítido quando perguntamos aos OP acerca do impacto das formações na prática docente:

Ele [o professor] faz a formação, mas depois ele não replica muitas vezes, acho que seria melhor perguntar para ele, né? Qual é essa dificuldade em trazer para a sua própria prática uma coisa que você está discutindo. Isso em vários casos a gente vê e fala "olha o professor sai para tratar de determinada questão", mas aquilo não muda na prática dele e muitas vezes ele talvez não consiga, mas aí ele tem a formação para isso (OP 1).

Acho que depende de cada um. A gente tem percebido coisas boas na nossa unidade, de professor participar [das formações] e trazer [contribuições]. Tem alguns professores que socializam, mas a gente percebe que tem essa necessidade de trazer algo, mas tem uns que nem tanto, então, vai muito do professor (OP 3). 
Podemos observar que não há consenso em relação às possibilidades de retorno à UE e ao coletivo de professores, socializando as aprendizagens, as reflexões e as proposições dos professores participantes de formação. Consideramos que isto se constitui em mais um grande desafio: construir mecanismos institucionais para envolver os professores de forma coletiva, a fim de discutir e refletir sobre o vivenciado por cada professor na formação de que participou. Acreditamos que este seja um caminho para o fortalecimento da escola como espaço de formação, onde se experiencia, coletivamente, o movimento de reflexão que pode promover mudanças.

É importante destacar que, na política de formação de professores do município, há modalidades diferentes ofertadas para a formação. Embora a quantidade maior seja de cursos de curta duração, há uma modalidade denominada Grupos de Formação ${ }^{\mathrm{iv}}$. Os OP relatam que a FCP em coletivos é mais significativa em relação às fragmentadas e pontuais. Para eles, os Grupos de Formação (GF) proporcionam o encontro de diferentes docentes e, coletivamente, discutem sobre problemas comuns e socializam experiências.

De qualquer modo, apesar de elogios feitos aos GF, eles são esvaziados em razão das impossibilidades de os professores participarem. Acreditamos que o professor deva ter o direito a uma formação continuada que vá ao encontro de suas necessidades específicas no nível pessoal (NÓVOA, 1992). No entanto, corroborando Moreto (2009), cremos que essas formações devam ser menos pontuais como um continuum de ações, levando marcas da cultura humana e da prática social e atendendo às necessidades do coletivo da UE.

Em síntese, o cenário no município em questão, segundo os OP, é de uma frágil relação entre a FCP e as mudanças nas práticas docentes e nas UE.

\section{Os princípios norteadores e as supostas (in)coerências entre o discurso da SME e a prática da escola}

Buscando refletir sobre a constituição e os princípios norteadores da formação continuada e as supostas (in)coerências entre o discurso da SME e a prática da UE na ótica dos OP no município em questão, dialogamos com alguns pesquisadores que abordam diferentes visões a respeito da FCP.

Vogt e Morosini (2012) mostram-nos a importância da FCP no espaço escolar. Outros pesquisadores, como Araújo e Silva (2009) e Davis et al. (2011), apontam que a FCP no país vem assumindo perspectivas antagônicas: liberal-conservadora e crítico-reflexiva; individualizada e colaborativa.

Para Araújo e Silva (2009), a formação continuada liberal-conservadora refere-se à atualização dos professores por meio de informações ou competências adquiridas em cursos, oficinas, seminários e outros. Nesse âmbito, o professor tem um papel secundário no processo formativo, ele reproduz o que foi pensado por especialistas. Já na tendência crítico-reflexiva, o professor assume uma centralidade em seu processo formativo, isto é, sua formação não depende exclusivamente de cursos (ou outras modalidades de formação), mas de suas próprias escolhas, muitas vezes, articuladas com sua atuação na UE. Neste caso, o docente 
caminha rumo a uma autonomia por meio de uma prática crítica-reflexiva em seu cotidiano de trabalho (ARAÚJO; SILVA, 2009).

Da mesma forma, segundo Davis et al. (2011), na ótica da formação individualizada, as ações põem o foco no professor com o intuito de reparar as falhas da formação inicial. Já a visão colaborativa valoriza o grupo de professores e defende a formação ocorrendo no interior das UE.

Do nosso ponto de vista, a concepção de formação continuada articula-se com as modalidades que ela assume em suas diferentes ofertas, que, por sua vez, darão mais ou menos oportunidades de diálogo e reflexão por parte dos professores. Conforme o disposto nas Diretrizes de Formação do município investigado, identificamos a oferta de duas modalidades formativas: a formação continuada com liberação integral periódica, que contempla a participação em diferentes cursos fora do espaço da UE, emitindo parecer em conjunto com a representação regional e em conformidade com a política de educação do município; e a formação continuada no trabalho, que necessita de pareceres conjuntos das instâncias envolvidas, como grupos de estudos nas escolas, cursos no centro de formação e eventos técnico-científicos.

A partir dessas teorias e dos dados empíricos, observamos que na rede em questão há uma coexistência de modelos formativos, mas com ênfase nos cursos individualizados e de curta duração. Isto nos faz inferir sobre a existência de uma relação mais forte com a tendência liberal-conservadora e individualizada na medida em que os numerosos cursos demonstram uma preocupação com o fornecimento de informações e instrumentalização de seus docentes.

Entre os anos de 2010 e 2014, foram ofertadas mais de 70 (setenta) formações em média por ano. Um dos coordenadores entrevistados aponta que a relevância da FCP para a SME está no alto número de cursos oferecidos. Reconhecemos que tal destaque pode significar a valorização de ações volumosas visando à formação, com a intenção de oportunizar várias opções de escolha para os professores. Entretanto, é importante o alerta de que a quantidade de cursos é um aspecto a ser acompanhado de mecanismos reguladores de qualidade, em sintonia com as demandas da rede educacional e das UE.

A despeito dessas formações de caráter individual - em que cada professor escolhe o curso que deseja - e contando com uma grande variedade de cursos disponibilizados pela SME, visando atender às supostas "defasagens" formativas de cada professor, o que se tem de fato nessa rede pública são formações de interesse da SME que não necessariamente coadunam com as visões e necessidades das UE e dos professores.

Não podemos negar certo movimento da política de FCP dessa SME na direção de tendências crítico-reflexivas e colaborativas, por exemplo, os Grupos de Formação (GF), Grupos de Estudo e de Trabalho. Nesses grupos, sobretudo nos GF, os professores dispõem de maior autonomia no que se refere à proposições, se comparados aos outros cursos caracterizados por serem mais prescritivos. Segundo a visão dos OP, os GF são modalidades que proporcionam ao professor a possibilidade de encontrar-se com outros de sua área curricular e, dessa forma, trocar experiências relacionadas às suas áreas de atuação, 
pressupondo uma relação maior com as práticas no interior das UE. Esses grupos formativos (grupos de formação, de estudos e de trabalho) convergem com as ideias de Araújo e Silva (2009) ao afirmarem que o professor deve ser o protagonista de sua própria formação e, neste caso, o docente deve ser incentivado a se apropriar dos saberes em direção à autonomia.

A diversidade de formações individualizadas e colaborativas dessa rede municipal corrobora o ponto de vista de Davis et al. (2011), que sugerem justamente mesclas. No entanto, é preciso questionar, quais as condições para que os docentes possam participar dessas formações e se elas atendem às demandas dos professores e da UE como um todo. Não basta ter diversas modalidades de formação, tornando-se apenas formações de aparências ou, como diz um dos OP, "uma bela vitrine", se não se oportunizar condições mais eficazes para o maior envolvimento e engajamento dos professores.

Como mencionamos, há uma tendência de que as formações do município analisado ocorram nos espaços escolares. Tal tendência aponta, segundo Vogt e Morosini (2012), para a importância do papel do orientador pedagógico. Contudo, segundo os OP participantes da pesquisa, não há condições adequadas para que assumam também o papel de formadores, seja por falta de tempo pedagógico ou por falta de formação própria. Porém, os OP não devem ser os únicos responsáveis pela FCP.

Os grupos formativos que acontecem nas próprias UE assumem uma tendência de formação colaborativa, construindo um espaço de diálogo e de reflexão envolvendo toda a equipe pedagógica, constituindo-se em verdadeiras "comunidades de aprendizagens", com vistas à consolidação de um constante processo de formação continuada.

A tendência colaborativa das formações dessa rede municipal ocorre, cada vez mais, a partir de grupos formativos e no interior das UE, podendo revelar uma aproximação importante entre as UE e a SME. Podemos interpretar, no entanto, que esse movimento seja uma mera estratégia de corte de gastos, já que, neste caso, seriam utilizados quase todos os recursos da própria escola.

Embora uma formação colaborativa nas UE utilize seus próprios recursos, notamos, pelos relatos, que se faz necessário um investimento na composição da jornada de trabalho de cada um desses profissionais, a fim de que haja, de fato, a possibilidade de dedicação ao processo formativo, ampliando o trabalho pedagógico para discussões, trocas de experiências e reflexão sobre essas experiências e sobre os conhecimentos que as sustentam. Entendemos que essa perspectiva de formação possibilita o fortalecimento da UE como espaço formativo. Segundo Tassoni e Megid (2015, p. 207), "só com o fortalecimento da escola como um espaço de produção de conhecimento tanto para alunos como para professores é que podemos acreditar em mudanças de fato". Assim, pensar a FCP nessa perspectiva não combina com a ideia de redução de gastos. Ao contrário, é necessário investir muito na escola e na carreira do magistério.

A partir das entrevistas com os OP e da análise das Diretrizes de Formação, notamos que os grupos formativos tentam se avizinhar de uma epistemologia da prática, denominada por Schön (2000) de professor crítico-reflexivo, que enfatiza os movimentos de observação e 
de reflexão feitos pelo professor sobre e na sua prática pedagógica, levando à construção de saberes calcados na experiência.

Buscando, enfim, identificar as supostas (in)coerências entre o discurso da SME e a prática da UE no município investigado, em primeiro lugar, há que se considerar o inegável movimento por parte da SME no sentido de consolidar uma política pública de FCP no município, por meio da produção das Diretrizes de Formação que regulamentem o processo formativo. Contudo, vemos grandes desafios a serem enfrentados nesse processo, como a posição contrária dos professores em relação à dedicação exclusiva a uma única UE e a FCP de caráter obrigatório. Logo, essas divergências contribuem para o entrave na constituição de uma política de formação continuada que favoreça a todos os interessados e, acima de tudo, consiga contribuir para a melhoria da qualidade de ensino e aprendizagem nas UE.

É inegável o avanço da formação no município com remuneração das formações e com diferentes e numerosas ofertas de cursos e grupos formativos - sem contar eventuais dispensas dos professores para participarem de diferentes tipos de formações. Todavia, em nosso entendimento, esse percurso tem sido lento e com pouca participação dos professores e OP. Não por acaso, nas entrevistas os OP relataram não terem clareza sobre o processo de escolha das temáticas e as demandas dos cursos/grupos formativos. Há pesquisadores que apontam que a identificação e análise dessas necessidades formativas são cruciais para agir de forma coerente com a realidade que demanda (GALINDO; INFORSATO, 2008).

As incongruências podem estar relacionadas à não conclusão do documento sobre as Diretrizes de Formação. A morosidade na finalização desse documento revela, conforme aponta um dos coordenadores entrevistados, uma clara ligação com a política partidária, refletida na troca de pessoas em cargos de chefia estratégicos para a $\mathrm{FCP}$, o que, na visão de alguns OP, tem sido um entrave para a melhoria da política de FCP. Assim, ressaltamos que, a partir da análise dos dados, essa indefinição quanto à materialização dessa política acarreta ausência de clareza quanto ao papel do OP na FCP, impossibilitando um trabalho mais consistente junto aos docentes.

Isso nos revela o quanto os $\mathrm{OP}$ estão distantes de se reconhecerem também como formadores no espaço escolar, pois lhes faltam também as condições de tempo pedagógico com o coletivo de professores. Entendemos que a falta de tempo é, em parte, o reflexo do não cumprimento da Lei do Piso por parte do município. Se, por um lado, vemos alguns esforços da SME em construir uma política de FCP, por outro, notamos uma timidez no que se refere à questão central, ou seja, à inclusão do tempo formativo na jornada de trabalho dos docentes. Acreditamos que a resolução desse ponto, ao longo do tempo, faria com que os professores ingressantes nessa rede optassem por mais tempo de formação, em vez de incorporarem mais aulas em sua jornada semanal.

Sabemos que a FCP e os modelos adotados, por si só, não mudarão uma realidade complexa com diversos atores envolvidos (ARAÚJO; SILVA, 2009). Contudo, a FCP, aliada a outros fatores, possui uma considerável relevância nas mudanças educacionais, por isso tem sido alvo de muitas pesquisas acadêmicas (ARAÚJO; SILVA, 2009; DAVIS et al., 2011; VOGT; MOROSINI, 2012; TASSONI; MEGID, 2015). 
Há de se considerar que as ações formativas necessitam de avaliações e reavaliações, a fim de certificar em que medida se aproximam das exigências de realidades em constante mutação.

\section{Considerações finais}

A pesquisa aqui apresentada possibilitou problematizarmos as políticas educacionais e seus modelos formativos decorrentes. A valorização do treinamento de professores e o investimento por parte do Estado em priorizar formações aligeiradas e pontuais não têm impactado positivamente a prática do docente no interior das UE, na visão dos OP entrevistados.

A própria política de FCP do município, que disponibiliza grande quantidade de formação individualizada, oferece também a modalidade de Grupos de Formação - processo formativo coletivo que possibilita trocas mais significativas entre os docentes. Em tais grupos, professores de uma mesma área possuem a oportunidade de discutir as Diretrizes Curriculares e socializar experiências da prática. A pesquisa evidenciou que esse tipo de proposta de formação pode promover maior reflexão e autonomia ao professor.

Independentemente de tal tendência, é preciso garantir as condições mínimas para que os professores do ensino público possam se envolver cada vez mais com as propostas de FCP oportunizadas pela SME.

\section{Referências}

AGUIAR, Wanda Maria Junqueira de; OZELLA, Sergio. Apreensão dos sentidos: aprimorando a proposta dos núcleos de significação. Revista Brasileira de Estudos Pedagógicos. Brasília, v. 94, n. 236, p. 299-322, jan./abr. 2013.

ANDRÉ, Marli Eliza Dalmazo Afonso de. Estudo de Caso: seu potencial na educação. Cadernos de Pesquisa. São Paulo, n. 49, p. 51-54, maio 1984.

ARAÚJO, Clarissa Martins de; SILVA, Everson Melquíades da. Formação continuada de professores: tendências emergentes na década de 1990. Educação. Porto Alegre, v. 32, n. 3, p. 326-330, set./dez. 2009.

BOGDAN, Robert; BIKLEN, Sari. Investigação qualitativa em educação. Porto: Porto Editora, 1994.

BRASIL. Ministério da Educação. Lei de Diretrizes e Bases da Educação Nacional. Lei n ${ }^{\circ}$ 9.394, de 20 de dezembro de 1996. Diário Oficial da União, Brasília, DF, 23 de dezembro de 1996. 
BRASIL. Lei no 11.738, de 16 de julho de 2008. Disposições Constitucionais Transitórias, para instituir o piso salarial profissional nacional para os profissionais do magistério público da educação básica. Presidência da República. Brasília: DF, 2008.

BRASIL. Decreto no 7083, de 27 de janeiro de 2010. Disposições sobre o Programa Mais Educação. Presidência da República. Brasília: DF, 2010.

DAVIS, Claudia Leme Ferreira et al. Formação continuada de professores em alguns estados e municípios do Brasil. Cadernos de Pesquisa. São Paulo, v. 41, n. 144, p. 826-849, set./dez. 2011.

GALINDO, Camila José; INFORSATO, Edson do Carmo. Formação continuada errática e necessidades de formação docente: resultados de um levantamento de dados em municípios paulistas. Interacções. Portugal, n. 9, p. 80-96, 2008.

GATTI, Bernadete Angelina. Análise das políticas públicas para formação continuada no Brasil, na última década. Revista Brasileira de Educação. Rio de Janeiro, v. 13, n. 37, p. 5770, jan./abr. 2008.

LIMA, Marcio Javan Camelo de. Neoliberalismo e educação. Studia Diversa, CCAE-UFPB, v. 1, n. 1, p. 44-61, out. 2007.

MAUÉS, Olgaíses Cabral. Reformas internacionais da educação e formação de professores. Cadernos de Pesquisa. São Paulo, n. 118, p. 89-117, mar. 2003.

MORETO, Julio Antonio. Formação continuada de professores: dos (des) caminhos dos órgãos colegiados de participação, às instâncias de gestão das políticas públicas. 2009. $314 \mathrm{f}$. Tese (Doutorado em Educação). Universidade Estadual de Campinas, Faculdade de Educação, Campinas, SP, 2009.

NÓVOA, António. Formação de professores e profissão docente. In: NÓVOA, António (coord.). Os professores e a sua formação. Lisboa: Publicações Dom Quixote, 1992. p. 1333.

SAVIANI, Dermeval. História das ideias pedagógicas no Brasil. Campinas: Autores Associados, 2008.

SCALCON, Suze. O pragmatismo e o trabalho docente profissionalizado. Perspectiva. Florianópolis, v. 26, n. 2, p. 489-521, jul./dez. 2008.

SCHÖN, Donald A. Educando o profissional reflexivo: um novo design para o ensino e a aprendizagem. Tradução de Roberto Cataldo Costa. Porto Alegre: Artmed, 2000.

TASSONI, Elvira Cristina Martins; MEGID, Maria Auxiliadora Bueno Andrade. A formação de professores alfabetizadores e o Programa Ler e Escrever. ETD - Educação Temática Digital. Campinas, v. 17, n. 1, p. 193-210, jan./abr. 2015.

VOGT, Grasiela Zimmer; MOROSINI, Marília Costa. Formação continuada de professores e reunião pedagógica: construindo um estado de conhecimento. Reflexão e Ação. Santa Cruz, V. 20, n. 1, p. 24-37, jan./jun. 2012. 


\section{Notas}

${ }^{\text {i }}$ A pesquisa apresentada neste artigo foi financiada pela Coordenação de Aperfeiçoamento de Pessoal de Nível Superior (CAPES).

ii As referências do Diário Oficial do Município, bem como da Lei mencionada não serão apresentadas visando preservar a identidade do município investigado e os participantes da pesquisa.

iii A referência deste documento não será apresentada, visando preservar a identidade do município investigado e os participantes da pesquisa.

iv Os chamados Grupos de Formação (GF), modalidade nas quais professores da mesma área curricular se encontram e discutem currículo e metodologias. 